\title{
Management of giant hydatid cysts: a tertiary centre experience
}

\author{
Mahdi Abdennadher ${ }^{1,2^{*}}$ (D), Mariem Hadj Dahmane ${ }^{1,2}$, Hazem Zribi ${ }^{1,2}$, Sarra Zairi ${ }^{1,2}$, Imen Bouassida ${ }^{1,2}$, \\ Imen Sahnoun ${ }^{1,3}$, Henda Neji ${ }^{1,4}$, Mouna Mlika ${ }^{1,5}$, Sonia Ouerghi ${ }^{1,6}$ and Adel Marghli, ${ }^{1,2}$
}

\begin{abstract}
Background: Hydatid cyst $(\mathrm{HC})$, the most parasitic disease of the lung, is still an important health problem in Tunisia. In this study, we reviewed our experience in a surgical management of 33 patients with giant pulmonary hydatid cyst (GPHC) (diameter $\geq 10 \mathrm{~cm}$ ).

Main body: Between 1998 and 2019, a total of 33 patients with GPHC were operated in the Thoracic Surgery Department in Abderrahmane Mami Hospital. Seventeen were males (51.51) and 16 were females (48.48\%). The median age was 33.9 years (range 7-83 years). The diameters of the cyst ranged between 10 and $20 \mathrm{~cm}$ (mean $13.15 \mathrm{~cm}$ ). The most common symptoms were chest pain (63.63\%) and cough (33.33\%). Imaging showed a single GPHC in all cases. GPHC was intact in $75.75 \%$ cases and complicated in $24.25 \%$ cases. Posterolateral thoracotomy was performed in 27 cases (81.81\%). For the residual cavity, parenchyma-saving procedures were performed in $54.54 \%$ and anatomical resection was performed in $45.46 \%$. Morbidity was low, and no mortality was seen.
\end{abstract}

Conclusion: GPHC are considered more difficult to treat surgically than small cysts; parenchyma preserving should and could be the surgical method of choice with a good prognosis. The decision of anatomical pulmonary resection is taken in per-operative when conservative surgery is not possible.

Keywords: Giant pulmonary hydatid cyst, Anatomical resection, Cystectomy

\section{Background}

The $\mathrm{HC}$ is an anthropozoonosis due to the development of cysts corresponding to the larval form of a taenia called Echinococcus granulosus [1]. HC is still an endemic pathology in several countries, especially in the rural regions. In our country (Tunisia), it remains a real public health problem. Hydatidosis can be asymptomatic for many years. The symptoms are ranging from asymptomatic to severe dyspnea, cough, and chest pain and depend on many factors as well as the size [2]. HC of 10 $\mathrm{cm}$ or greater in diameter are considered "giant" cysts [3]. Surgery is the only curative treatment of the pulmonary hydatid cyst of any size. Surgery of GPHC,

\footnotetext{
*Correspondence: abdennadhermahdi@gmail.com

'Université El-Manar, Tunis, Tunisia

${ }^{2}$ Service de Chirurgie Thoracique et Cardiovasculaire, Hôpital Abderrahmane Mami, Rue del'Hôpital, 2080 Ariana, TN, Tunisia

Full list of author information is available at the end of the article
}

requiring sometimes pulmonary resection, is more difficult to operate than smaller cysts [3]. Cystectomy associated usually to a capitonnage is the conservative surgical method of choice and preserves lung tissues [4]. In this study, we report our 21 years of experience with giant hydatid cysts of the lung.

\section{Main text}

Patients and methods

Between January 1998 and December 2019, thirty-three patients were operated on for GPHC in the Department of Thoracic Surgery of Abderrahmane Mami Hospital in Tunisia. Pulmonary hydatid cysts measuring more than $10 \mathrm{~cm}$, in the largest diameter, were defined as giants. The size of the cyst was determined by conventional radiography, computerised tomography, and/or intraoperative finding or a combination of the three. Chest radiography was performed in all cases. Abdominal

\section{Springer Open}

(c) The Author(s). 2021 Open Access This article is licensed under a Creative Commons Attribution 4.0 International License, which permits use, sharing, adaptation, distribution and reproduction in any medium or format, as long as you give appropriate credit to the original author(s) and the source, provide a link to the Creative Commons licence, and indicate if changes were made. The images or other third party material in this article are included in the article's Creative Commons licence, unless indicated otherwise in a credit line to the material. If material is not included in the article's Creative Commons licence and your intended use is not permitted by statutory regulation or exceeds the permitted use, you will need to obtain permission directly from the copyright holder. To view a copy of this licence, visit http://creativecommons.org/licenses/by/4.0/. 
ultrasonography was performed in 27 patients to asses for concomitant hepatic cyst. Computed tomography scan of the chest (CT) was done in all cases of giant hydatid cysts. A retrospective analysis was performed using clinical characteristics, biologic tests, radiologic investigations, and surgical procedures. The follow-up postoperatively was performed for $1 \pm 5$ years.

\section{Results}

For 21 years, we have operated 33 GPHC in our department. The median age was 33.9 years (range 7-83). Most patients $(69.69 \%)$ were under the age of 40 (Table 1 ). The gender ratio $(\mathrm{F} / \mathrm{M})$ was 1.06 . The diameters of the cysts ranged between 10 and $20 \mathrm{~cm}$ (mean $13.5 \mathrm{~cm}$ ). Most patients were from rural areas; parasitic exposure was found in $80 \%$ of the cases. The most common symptoms was chest pain (63.63\%), cough (33.33\%), and shortness of breath (24.24\%). Hemoptysis was observed in $(12.12 \%)$ of cases. The most common general sign was fever (9.09\%). Hydatoptysis, the only diagnostic symptom of pulmonary hydatid disease, was observed in one case (Table 2).

Imaging tools showed a single GPHC in all cases. Associated hydatic lesions were seen in the liver in one case. Out of a total of $33 \mathrm{GPHC}, 16$ were located to the right lung and 17 were located to the left lung. The giant cysts were located in lower lobes in 24 cases (72\%) (Table 3). Twenty five cysts were intact and 8 were complicated (Figs. 1 and 2) (ruptured in the bronchial a vérifier). The most common finding on the CT scanning of patients with intact GPHC (Fig. 3) was a smoothly outlined, dense spherical opacity. The prominent radiologic finding of complicated $\mathrm{HC}$ was the presence of an airfluid level (12.12\%) (Fig. 2). A suppurated cyst was observed in 3 cases.

All the patients were operated. Twenty seven (81.81\%) of patients were approached via a posterolateral thoracotomy, which was performed through the 5th or 6th intercostal space, depending on the location of the GPHC. Lateral approach was performed in 6 patients (18.19\%). First, to prevent contamination to the lung parenchyma and parietal pleura, we protected the operative field with compresses soaked in betadine (iodized polyvidone $(10 \%)$ ) or hypertonic solution $(30 \%)$ (sodium chloride solution). Hydatid fluid was aspirated from the top of the cyst with 20-G needle to reduce the intracystic pressure. The cyst was opened with $1-$ or $2-\mathrm{cm}$ incision, and the suction apparatus was inserted into cystic

Table 1 Age distribution of 33 patients with GPHC

\begin{tabular}{ll}
\hline Age (years) & Number of the patients \\
\hline 40 & 23 \\
$>40$ & 10 \\
\hline
\end{tabular}

Table 2 Symptoms of GPHC cases

\begin{tabular}{lll}
\hline Signs & Number of cases & $\%$ \\
\hline Pain & 21 & 63.63 \\
Cough & 13 & 33.33 \\
Shortness of breath & 8 & 24.24 \\
Hemoptysis & 4 & 12.12 \\
Fever & 3 & 9.09 \\
Hydatoptysis & 1 & 3.03 \\
\hline
\end{tabular}

cavity to evacuate the remaining fluid. The germinal membrane was removed with forceps. After verifying that the lung was freed from adhesion, the thinner pericystic tissue was incised by electrocautery and the cavity was cleaned with suction apparatus and compress soaked in betadine. To look for bronchial fistula, we filled the residual cavity with a physiologic serum, and we inflated the lung, checked for air leaks, and sutured any bronchial fistulas.

A lobectomy was performed when, after removal of the cyst, the lung tissue was found to be destroyed due to prolonged compression of infection.

Cystotomy, cystectomy plus closure of the bronchial opening if there exists a capitonnage of the residual cystic space performed in 18 patients (54.54\%), was the most frequently applied operation procedure. In 15 cases $(45.45 \%)$, anatomical resection (lobectomy ( $n$ = 13) $39 \%$ and bilobectomy lower $(n=2) 6 \%$ was achieved due to the presence of parenchyma damage more than $50 \%$ of a lobe in 12 cases and for sequelae of chronic abscess in 3 cases.

The most common postoperative complication was a prolonged air leak (9.09\%). Other postoperative complications seen is pneumonia in one case (Table 4). Medical therapy with albendazole was not given in all the cases. Anatomopathology confirmed pulmonary hydatidosis in all cases. No secondary pleural hydatidosis or recurrent $\mathrm{HC}$ was recorded in $1 \pm 5$ year's follow-up postoperatively during what imaging investigations were made to control the parenchyma. There was no operative mortality, which was defined as death from any cause during hospitalisation and within 30 days of the operation. To avoid the recurrence of $\mathrm{HC}$, a hygienic advice was given to patient in control consultation.

Table 3 Location of GPHC

\begin{tabular}{ll}
\hline Location & Number of patients \\
\hline Right upper lobe & 1 \\
Right lower lobe & 13 \\
Right middle & 2 \\
Left upper lobe & 6 \\
Left lower lobe & 11 \\
\hline
\end{tabular}




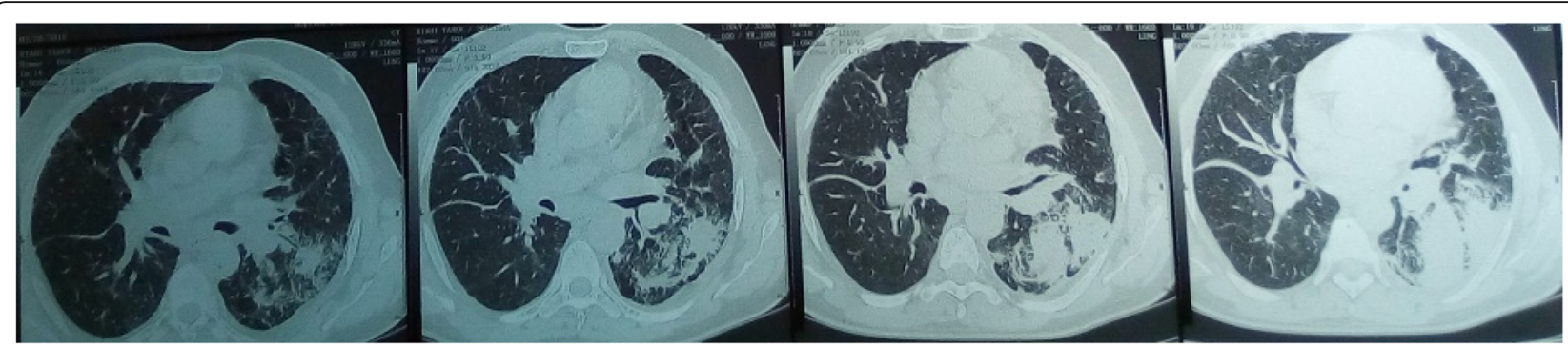

Fig. $1 \mathrm{CT}$ appearance of a complicated giant hydatid cyst $(10 \mathrm{~cm})$ of the left lower lung lobe required a lobectomy

\section{Discussion}

Hydatid disease is the most common human cestodiasis [5]. The $\mathrm{HC}$ is an anthropozoonosis due to the development of cysts corresponding to the larval form of a taenia called Echinococcus granulosus [1, 6]. This parasitic disease is still endemic in Tunisia. The liver and secondly the lungs are the two most common locations of hydatid cyst $[1,2,7,8]$. In the diagnosis at an advanced stage of the disease, the hydatic cyst of the lung is correlated with more infectious and compressive complications due to increased size. Giant hydatid cysts of the lung constitute a particular clinical entity most frequently encountered mainly in younger patient [6]. The right lower lobe location is generally the predominant lung location $[5,10]$. In our study, the most frequent localisation of the GPHC was the right lower lobe $(39.39 \%)$ as cited in the literature.

Lung tissue has more elasticity and compliance than other organs so that $\mathrm{HC}$ typically grows quickly than in others tissues $[3,7,10]$. In addition, the peripheral location of the cyst gives rise to an increase in size more easily than a central cyst since in the latter, the main vascular structures and bronchi will limit growth of the cyst [11]. The HC in the lung enlarges in size depending also on the patient's immune response and pulmonary reserve [7]. Moreover, in the literature review, it has been reported that the immune system and the relatively higher elasticity of the lung parenchyma in children and the adolescent allows the rapid growth of cyst, and hence giant hydatid cysts are more commonly seen in young people than in elderly people. In our study, most of our patients (69.69\%) are younger than 40 years.

There is no universally accepted size to define a pulmonary hydatid cyst as "giant" [7, 8]. However, according to the majority of articles published, it was agreed that $10 \mathrm{~cm}$ or more defined the size of giant hydatid cysts of the lung $[5,7,12]$. Compared to smaller cysts, GPHC require various surgical techniques that depend on per-operative founding. Generally, the lung hydatid disease is asymptomatic for a long time until occurrence of local or general complications such as rupture into the bronchi and pleural cavity or vital organ compression $[3,13]$. Those complications are more frequent in case of GPHC due to the size of the cyst, and so symptoms appear usually $[1,3,9]$. In our study, all patients were symptomatic.

Generally, the diagnosis of hydatid disease is easy in endemic areas [7]. Chest X-ray provided accurate

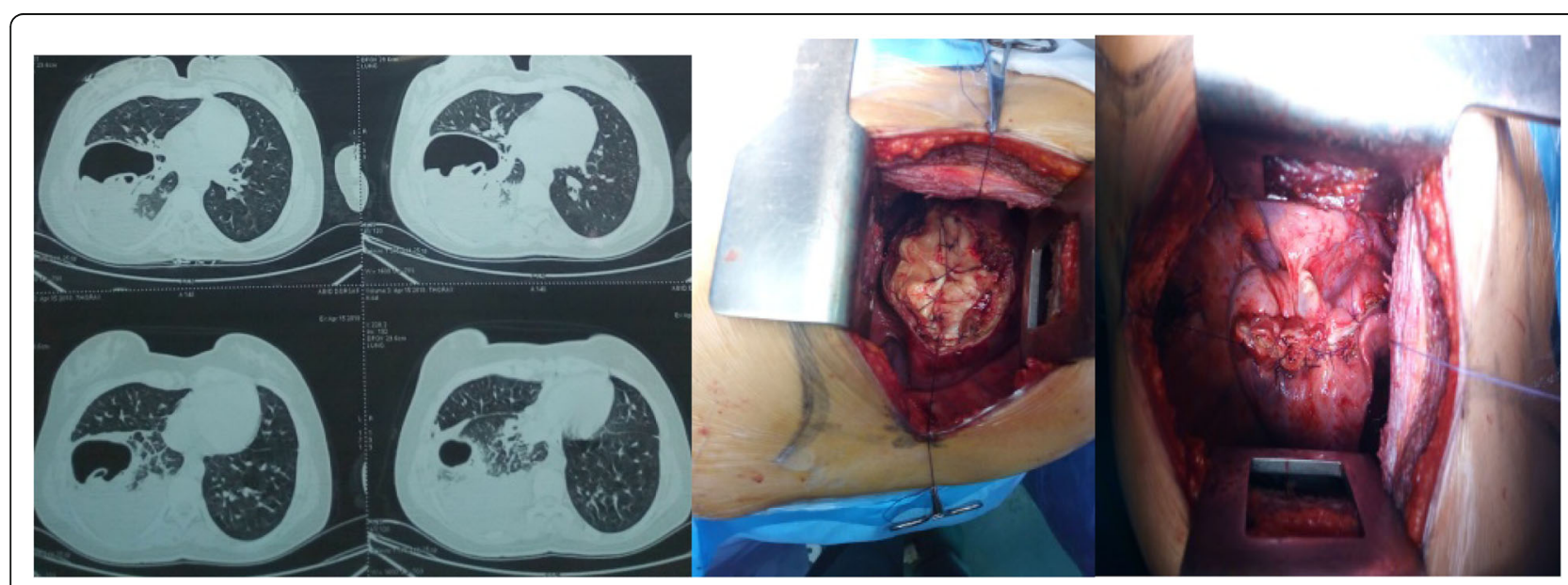

Fig. 2 a CT appearance of a complicated giant hydatid cyst (air-fluid level) of the right lower lung lobe. b Per-operative photo showing the capitonnage 


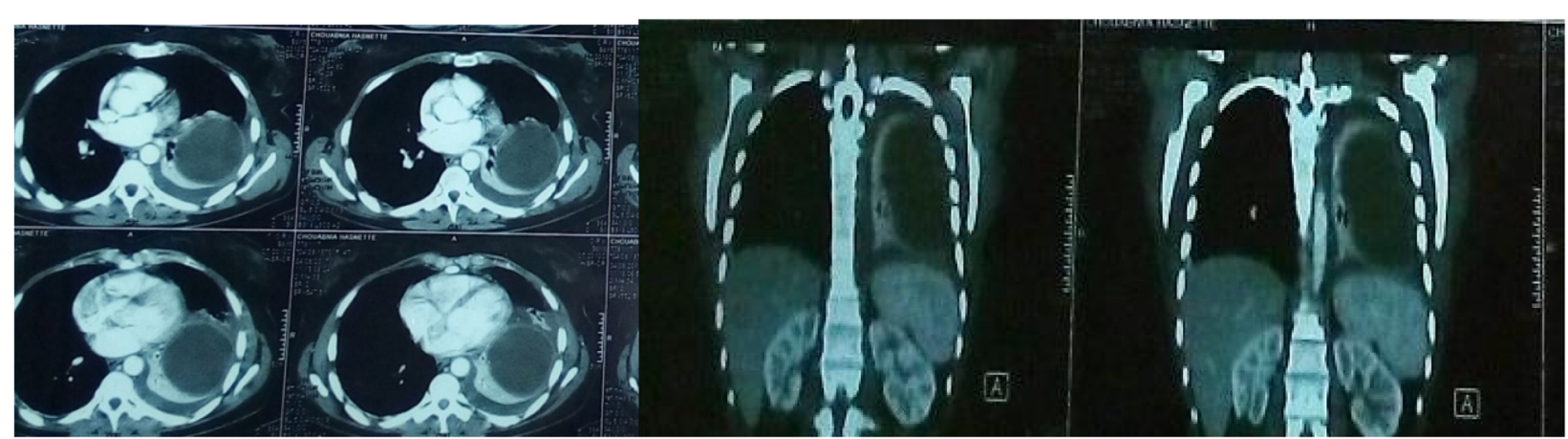

Fig. $3 \mathrm{CT}$ appearance of intact giant hydatid cyst $(12 \times 13 \mathrm{~cm})$ of the left lower lobe (parenchymal damage $>2 / 3$ lobe) required a lobectomy

diagnosis of GPHC in $93.4 \%$ of cases [7]. The CT scan is not mandatory for diagnosis, but in case of GPHC, it enables to specify the size of the cyst and allows better information about the extent of the cyst in lung parenchyma, bronchi, and pulmonary vessels [12]. Occasionally, complicated GPHC constitute diagnostic challenges on imaging, and the per-operative exploration is the only one that provides a final diagnosis [8].

The surgical challenge in GPHC is to remove the giant cyst while preserving as much lung tissue as possible [7]. Decision-making criteria in the choice of operative techniques differ from one country to another and are inextricably depending to the thoracic surgeon's experience with the lung hydatid disease [7]. In addition, usually, it can be difficult to predict preoperatively whether anatomical resection will be required.

Surgical approaches in our study were posterolateral or lateral thoracotomy depending on the cyst location. We did not use VATS in our patients because in case of intact cyst which is under tension and seen the risk of rupture, we prefer to avoid introduction of trocar; secondly, we might have enough access to thoracic cavity in order to perform laborious capitonnage.

The size of the $\mathrm{HC}$ and the presence of complications are the most commonly accepted criteria for deciding which surgical technique should be performed [7]. Is widely accepted that lung-preserving parenchyma-surgery is preferable [13]. Cystotomy with capitonnage after the closure of small bronchial communication or fistula constitutes the routine conservative surgical techniques of the GPHC [1]. It is believed that those procedures should be preferred in most cases because the lung parenchyma that has been compressed by the cyst is healthy and would expand postoperatively. Anatomical resection should be avoided whatever the cyst size [1]. However, for many authors, it is advised to perform an anatomical resection when giant cysts occupying the entire lobe and if GPHC is associated to complications (suppuration, chronic abscess, fibrosis, haemorrhage...) that causes parenchymal damage by involving more than $50 \%$ of a lobe $[1,3,10]$. For other authors, the decision of anatomical pulmonary resection are taken in per-operative, after aspiration of cystic fluid, the closure of bronchial openings, excision of the cyst, and testing of the lung re-expansion of the remaining lobe.

In our study, anatomical resection is relatively high and was performed in 15 patients (45.46\%). Six patients had a complicated large cyst ( mainly hemoptysis), and nine had an intact GPHC, which is associated with lung resection irreversible damage which have occurred throughout the lungs by involving more than $50 \%$ of a lobe or those that are associated with such sequelae such as chronic abscess, bronchiectasis, or severe haemorrhage; thus, lobectomy or bi-lobectomy is required.

Two main reasons argue for lung-preserving parenchyma surgery and push the surgeon to avoid anatomical resection. First is the high probability that the pulmonary parenchyma remaining after conservative surgical procedure can ensure satisfactory re-expansion of the lung. Secondly, mainly in the endemic country, there is a higher risk of recurrence of hydatid disease and so the possibility of iterative surgery of hydatid cyst [10].

Morbidity rate of GPHC surgery can be very low with a negligible mortality rate, if the capitonnage is properly performed, and the bronchial openings are firmly closed

Table 4 Surgical procedure, complicated uncomplicated status of the cysts, and their correlations with postoperative complications

\begin{tabular}{|c|c|c|c|c|c|c|}
\hline & \multicolumn{3}{|c|}{ The operation types } & \multicolumn{3}{|c|}{ Postoperative complications } \\
\hline & Lobectomy & Bilobectomy & Cystotomy + cystectotomy + capitonnage & Pneumonia & Prolonged air leak & Simple \\
\hline Complicated cysts $(N=8)$ & 5 & 1 & 2 & 1 & 0 & 7 \\
\hline Simple cysts $(N=25)$ & 8 & 1 & 16 & 0 & 3 & 12 \\
\hline
\end{tabular}


[3]. The complication rates reported in the literature varies between 17 and 19\% in giant hydatid lung cysts [6]. In our study, the complication rate was $24.25 \%$. Even though GPHC in our study were likely to require anatomic lung resection, we were able to perform parenchyma-sparing operations in $54.54 \%$ of the cases.

Preoperative medical treatment with albendazole (ABD) treatment decreases the tensile strength of the cuticular membranes of pulmonary $\mathrm{HC}$ and might cause rupture of the cyst. Therefore, it should not be applied to patients who are candidates for surgery. Perhaps, it can be administered preoperatively, for patients with multiple cysts or ruptured ones. In postoperative, $\mathrm{ABD}$ can be given to patients having a risk of intraoperative spillage or patients with giant cysts to prevent recurrence [14]. For other authors, it is postoperatively administered medical therapy only if daughter cysts are detected during the operation [8]. In disseminated and nonoperable cases of lung $\mathrm{HC}$, therapy with $\mathrm{ABD}$ can be used as an alternative to surgery. In conclusion, reported in the literature and our experience, we think that medical treatment with $\mathrm{ABD}$ of $\mathrm{HC}$ of the lung should be performed in inoperable cases and can be used during the postoperative period, in order to prevent the recurrence and occurrence of a secondary cyst $[3,12]$.

\section{Conclusion}

Giant hydatid lung cysts represent a distinct entity .We found that GPHC was more prevalent in younger patients. Surgery is the gold standard in management of hydatid disease. Due to the potential complication of giant lung cyst due the size, we should perform surgical treatment as soon as the diagnosis is made. Conservative surgical methods preserving lung parenchyma are usually preferred, whether the $\mathrm{HC}$ was giant or small, and can be safely performed, with low morbidity and negligible mortality rates. We must not forget the great place of prevention in management of hydatidosis mainly in countries where the disease is endemic.

\section{Abbreviations}

GPHC: Giant pulmonary hydatid cyst; HC: Hydatid cyst; CT: Computed tomographic; ABD: Albendazole

\section{Acknowledgements}

Not applicable

Studies involving plants must include a statement specifying the local, national, or international guidelines and legislation and the required or appropriate permissions and/or licences for the study Not applicable.

\section{Authors' contributions}

AM and HM analysed and interpreted the patient data regarding the characteristic and management of giant cyst. MM performed the histological examination. $\mathrm{NH}$ interpreted the $\mathrm{CT}$ scan of patients. AM was a major contributor in writing the manuscript. OS and MA performed the critical revision. All authors read and approved the final manuscript.

\section{Funding}

No funding support
Availability of data and materials

Data available on request from the authors

\section{Declarations}

Ethics approval and consent to participate

Not applicable

\section{Consent for publication}

Not applicable

\section{Competing interests}

The authors declare that they have no competing interests.

\section{Author details}

${ }^{1}$ Université El-Manar, Tunis, Tunisia. ${ }^{2}$ Service de Chirurgie Thoracique et Cardiovasculaire, Hôpital Abderrahmane Mami, Rue del'Hôpital, 2080 Ariana, TN, Tunisia. ${ }^{3}$ Service de Pneumologie (Pav D), Hôpital Abderahmen-Mami, Ariana, Tunisia. ${ }^{4}$ Service de Radiologie, Hôpital Abderrahmane Mami, Ariana, Tunisia. ${ }^{5}$ Service d'Anatomopathologie, Hôpital Abderrahmane Mami, Ariana, Tunisia. 'Service d'Anesthésie Réanimation, Hôpital Abderrahmane Mami, Ariana, Tunisia.

Received: 4 January 2021 Accepted: 25 April 2021

Published online: 03 May 2021

\section{References}

1. Sajiai H, Rachidi M, Aitbatahar S, Serhane H, Amro L (2016) Kyste hydatique pulmonaire: double localisation pulmonaire apicale inhabituelle: à propos d'un cas. Pan Afr Med J 25:159

2. Armin A, Bizhan Z, Amirhossein E, Reza S, Keivan R (2020) Successful management of a huge pulmonary hydatid cyst with lung-preserving surgery. Case Rep Surg 2020:9526406. https://doi.org/10.1155/2020/9526406

3. Usluer O, Can Ceylan K, Kaya S, Sevinc S, Gursoy S (2010) Surgical management of pulmonary hydatid cysts: is size an important prognostic indicator? Tex Heart Inst J 37(4):429-434

4. Aldahmashi M, Alassal M, Kasb I, Elrakhawy H (2016) Conservative surgical management for pulmonary hydatid cyst: analysis and outcome of 148 cases. Can Respir J 2016:8473070

5. Racil H, Ben Amar J, El Filali Moulay R, Ridene I, Cheikrouhou S, Zarrouk M et al (2009) Kystes hydatiques compliqués du poumon. Rev Mal Respir 26(7): 727-734. https://doi.org/10.1016/S0761-8425(09)72423-4

6. Arroud M, Afifi MA, El Ghazi K, Nejjari C, Bouabdallah Y (2009) Lung hydatic cysts in children: comparison study between giant and non-giant cysts. Pediatr Surg Int 25(1):37-40. https://doi.org/10.1007/s00383-008-2256-z

7. Halezeroglu S et al (1997) Giant hydatid cysts of the lung. J Thorac Cardiovasc Surg 113(4):712-7.

8. Ghallab NH, Alsabahi AA (2008) Giant viable hydatid cyst of the lung: a case report. J Med Case Rep 2(1):359. https://doi.org/10.1186/1752-1947-2-359

9. Yalçinkaya I, Er M, Ozbay B, Uğraş S (1999) Surgical treatment of hydatid cyst of the lung: review of 30 cases. Eur Respir J 13(2):441-444. https://doi. org/10.1183/09031936.99.13244199

10. Karaoglanoglu N, Kurkcuoglu IC, Gorguner M, Eroglu A, Turkyilmaz A (2001) Giant hydatid lung cysts. Eur J Cardiothorac Surg 19(6):914-917. https://doi. org/10.1016/S1010-7940(01)00687-X

11. Dakak M, Caylak H, Kavakli K, Gozubuyuk A, Yucel O, Gurkok S et al (2009) Parenchyma-saving surgical treatment of giant pulmonary hydatid cysts. Thorac Cardiovasc Surg 57(3):165-168. https://doi.org/10.1055/s-2008-1039210

12. Bouchentouf $R$, Benjelloun A, Chafik A, Aitbenasser MA (2012) Giant viable hydatid cyst of the lung revealed by hiccups. Pan Afr Med J 13:48

13. Kanat F, Turk E, Aribas OK (2004) Comparison of pulmonary hydatid cysts in children and adults. ANZ J Surg 74(10):885-889. https://doi.org/10.1111/j.144 5-1433.2004.03022.x

14. Usluer O, Ors Kaya S, Samancilar O, Can Ceylan K, Gursoy S (2014) The effect of preoperative albendazole treatment on the cuticular membranes of pulmonary hydatid cysts: should it be administered preoperatively? Kardiochir Torakochirurgia Pol 11(1):26-29. https://doi.org/10.5114/kitp.2014.41926

\section{Publisher's Note}

Springer Nature remains neutral with regard to jurisdictional claims in published maps and institutional affiliations. 